\title{
Globalization: Mental Health and Social Economic Factors
}

\author{
VISHAL BHAVSAR \\ Guy's Hospital, UK \\ DINESH BHUGRA \\ King's College London, UK
}

\begin{abstract}
Aв STRACT Several factors associated with globalization have mental health consequences. This article reviews the literature on mental health and inequality, occupational patterns and identity shifts before considering the role of globalization as an acculturative stressor. We argue that a re-evaluation of mental health policy in light of globalization must look further than current studies of migrants to consider indigenous communities where models of social experience and behaviour are changing.
\end{abstract}

KEYWO RD S economic factors, globalization, mental health, social and cultural factors

\section{Introduction}

The increasing social, economic and cultural interconnection between communities has made mobility - social, individual, and that of goods and ideas very easy. The implications of such a massive transformation in human relations can be seen at various levels: individual, local, national, regional and supra-regional. The changes associated with these processes are key to understanding the responses of individuals and governments. The additional impact of multinational corporations and economic rationalizations on individuals, cultures and the functioning of the body politic have to be understood in the context of globalization. The interaction of cultural beliefs across communities, whether 
they are in geographical contact or indirectly exposed, can lead to changes in individuals as a result of acculturative processes. These processes change the way people view their own cultural values and those from other parts of the world. It is entirely likely that when two cultures come into contact, either through trade or through media, their expectations of each other and of themselves also change. Altered economic growth can further add to this stress and contribute to mental health problems.

It can be said that we are now accustomed to the 'brave new world of globalization' (Bhugra and Mastrogianni, 2004: 10) and to the discourses that surround it. A very general economic definition of globalization is the 'worldwide process of homogenizing prices, products, wages, rates of interest and profits' (Shariff, 2003: 163-78). Commentators outside the economic discipline define it in even broader terms as 'a process in which the traditional boundaries separating individuals and societies gradually and increasingly recede' (Okasha, 2005: 1-2). As Grint (2005: 360) points out, the large-scale movement of goods across national boundaries has a long history, involving organizations such as the Muscovy Company (1555) and the East India Company (1600). Manifestations of globalization have been cited as including rapid communication, cheap modes of travel, commercial deregulation, the growth of international political organizations and increasing cross-cultural communication (Okasha, 2005: 1-2). Importantly, however we choose to define globalization, we should note that the social processes associated with it have direct bearing on both individuals and communities in turn. In this article we discuss some of these interactions and their manifestations in relation to mental health. The American Psychiatric Association's (2000) most current Diagnostic and Statistical Manual defines mental disorder as 'a clinically significant behavioural or psychological syndrome or pattern that occurs in an individual and that is associated with present distress or disability'. There is no doubt that globalization continues to divide commentators over the benefits and costs it confers on the world in general and on countries in particular. With specific application of these concepts to health, Martin (2005: 1-2) has pointed out that 'the effects of globalization on health (and health systems) are neither universally good nor bad, but context specific'. It is also the case that the health effects of economic changes are likely to be change specific, and that individual economic processes should be addressed separately.

A group of related economic phenomena that include outsourcing, labour market deregulation and the increasing flexibility of work processes has fundamentally altered the individual experience of working life and influenced the mental health environment. The growth of the high technology sector and financial services has paralleled the decline of manufacturing and traditional industries in a so-called deindustrialization pattern. In recent years we have witnessed incidences of downsizing as organizations shift the site of labour from the core of organizations to the periphery, leading to the loss of jobs for reasons other than performance (Capelli, 1999: 96). Rapid economic 
growth has been associated with large internal migration of workers from rural to urban settings (Li et al., 2006: 2). Organizations based in developed countries have outsourced services to countries where labour is cheaper and the degree to which labour protection mechanisms are in place may be less than in other, often wealthier nations (Dicken, 1998). Although productivity has increased as a result of transformed systems of communication and flexible manufacturing, there has been a consequent decrease in dependence on human labour (Winefield et al., 2002: 5).

Our analysis is divided into five sections. We begin by considering the literature on mental health and inequality and then move on to the relationship between mental health and occupational patterns. The third section considers the impact of identity shifts on mental health. The fourth section examines the role of globalization as an acculturative stressor and the implications of this development. The fifth section of the article develops the concluding argument that a re-evaluation of mental health policy in light of globalization must look further than current studies of migrants to consider indigenous communities where modes of social experience and behaviour are changing.

\section{Inequality and Mental Health}

In Organisation for Economic Co-operation and Development (OECD) countries, consensus has emerged that globalization, including not only increased trade but international migration and capital flows, has contributed modestly to increased inequality by increasing wage differentials between skilled and unskilled workers. Observers have identified trends in the way that income is distributed within societies; the gap between average earnings for a college graduates and non-college graduates was $38 \%$ in 1979 while by 2000 the figure was $78 \%$ (The Economist, 2000a). The OECD report Income Distribution in OECD Countries identifies important patterns of wealth distribution. Between the mid-1980s and 1990s, the richest 30\% increased their market share in all the OECD countries, while the poorest $30 \%$ reduced their income share in all countries except the USA. The overall trend within wealthy countries has leaned therefore towards a widening of income distribution between the rich and the poor. There is no doubt that new economic practices have increased inequality by increasing the spread of wages between skilled and non-skilled workers. This trend has been seen not only in OECD countries but also in some middle income developing countries (Kohl and O'Rourke, 2000: 1). Katz (2000) has suggested that the deregulation of labour markets has similarly played a role in increasing income inequality within nations. As well as affecting wealth distribution within countries, economic liberalization has also affected the distribution of wealth between countries. Kelly (2003) cautions that globalization will have a net result of increasing inequality among the world's population: 
Market deregulation favours the dominant, strong economies of the West and fails to offer developing countries an opportunity to strengthen their infrastructure sufficiently to compete in a global economy. Globalization, by this logic, will lead to further poverty, inequality and social injustice. (Kelly, 2003: 465)

On the basis of this and other evidence, the view that modern socio-economic processes are exacerbating wealth inequalities instead of diminishing them has been well established by the existing literature.

One can use much of this evidence to argue that globalization has resulted in an increase in social inequality. However, it would be inaccurate to say that globalization has not brought some economic success for countries outside the 'developed world'. For example, the proportion of the global population living on less than US\$1 a day fell between 1987 and 1993 from 30\% to 29\%. In 2001, the UN Human Development Report was able to state for the first time that the majority of the world lived in a developed country, though this probably attests to massive economic migration, rather than economic development in the developing world.

The impact of social inequalities on the health of populations has been contested. Although many studies have reported better health and mortality indices in egalitarian societies (Subramanian and Kawachi, 2004: 89), a smaller number of studies have found no evidence to support an association (Deaton and Lubotsky, 2003: 1147; Lynch et al., 2004a: 386-91; Osler et al., 2002: 3). However, Wilkinson and Pickett (2006: 1774-5), in a systematic review of analyses of income inequality, have pointed out that studies which found no association between inequality of income and health tended to be smaller in geographical and population coverage and hence less reflective of social stratification, for which income inequality is a marker. Furthermore, psychosocial problems, namely violence and suicides, tend to be higher in lower income areas (Wilkinson, 2004: 1-12). Given the widespread positive association between income inequality and physical health, an association between mental health and social inequality seems likely. For example, Lynch et al. (2004b: 370) have reported similarity between 100-year trends in suicide and income inequality in the USA. Though they were unable to control for the impact of other social factors, it is still likely on the basis of this evidence that levels of social inequality do have some effect on rates of suicide. Eibner et al. (2004: 167-75) were able to correlate an index of relative deprivation with higher risks of developing depression and anxiety. Kahn et al. (2000: 1314) have found an association between living in an income unequal area with depression in women, although other studies (Sturm and Gresenz, 2002: 2-5; Weich et al., 2001: 224-7) have found weaker associations, casting doubt on this relationship. Yet the relationship between gender and income inequality means that the social limitations placed on females is likely to lead to a further sense of lowered expectation, achievement incongruence and powerlessness. This in turn is likely to influence self-esteem and result in psychological morbidity. 
Although an association between income inequality and mental health is not universally accepted, more recently a positive linear relationship between income inequality (measured by the ratio of the income share of the richest $20 \%$ of the population to the poorest $20 \%$ ) and the prevalence of any mental disorder in developed countries has been observed by Pickett et al. (2006: 646). As more data are gathered on the relationship between psychological functioning and social inequalities in low and high income countries, it will become possible to delineate more precisely the relationship between income inequality, mental disorder and deprivation in the 'developed' and the 'developing' world. There exist a number of putative mechanisms for the association between mental health and income inequality. Among them are differences in levels of social trust and cohesion (Wilkinson, 2005), the development of a negative view of one's status and worth (Charlesworth et al., 2004: 53-5), and a perceived loss of control over one's work and life (Marmot, 2004: 299-303).

In economic terms, the profound change in the social and psychological dimensions of work accompanying patterns of globalization has been articulated in terms of the growth of an informal sector of employment, defined by low earnings, the absence of contracts, unstable working conditions, poor access to social services, low rates of union affiliation and growing levels of irregular and quasilegal labour. This trend has been visible in the growing preponderance of temporary and part-time workers within the global labour market. In 1997, regular full-time workers represented $69 \%$ of the total workforce in the USA (Upjohn Institute, 1997). Data from the investment bank Morgan Stanley Dean Witter suggested that the majority of new jobs created between the years 1994 and 1998 were either part time or temporary (Beneria, 2001; The Economist, 2000b). In Latin America, $47.9 \%$ of total urban employment was informal in nature, while in 1990 it had been 44.4 \% (International Labour Organisation, 1999). This evidence leads us to the conclusion that the environment of employment both in wealthy and developing countries has shifted in a fundamental way. A traditional model of stable, reliable employment has given way to a new experience of working life. At the beginning of the 21st century, the average American 32-year-old male had worked for nine different employers - a shift away from the traditional archetype of the slow and steadily ascending career worker who remains with a single employer or very few employers. Average job tenure for 28-year-olds has similarly fallen since 1983. These data raise some important questions - if economic imperatives are transforming the working world, then what impact could this be having on psychological functioning?

\section{Occupation Patterns and Mental Health}

A number of studies have shown that adverse features of the psychosocial work environment can affect the rates of mental disorder among individuals 
(see for a review Stansfeld and Candy, 2006). However, there have been disagreements over the triggering factors. Some authors (such as Niedhammer et al., 2004: 1531, 2006: 118) have asserted the importance of workplace organizational factors such as leadership structure and effort-reward balance. Others, such as Muntaner et al. (2004: 398), have asserted that in the case of low income nursing home staff in the USA, the effects of workplace and organizational factors on mental health could not be isolated from income, i.e. among this group particular types of workplace environment were a source of stress when combined with a low income. The relationship between workplace organizational structure and low income may then be synergistic as regards mental health. In a comparative analysis of psychological morbidity among nursing home staff, Muntaner et al. (2006: 695) found that income inequality and loss of social cohesion were not significant correlates of mental ill health once workplace organizational factors had been accounted for.

There may be a risk, then, in apportioning blame for mental health deficits on the organization of the workplace when low income and poverty play a more direct role in the genesis of mental disorders. Although much of this work has been rather limited in its geographical scope, it has proven useful in delineating the sorts of factors that might be in play as workforces change in response to the forces of globalization. It is probable that organizational factors have a role in exacerbating the stressing effect of the low income state. Even those whose incomes rise as a result of the globalized workplace may find there is a mental health cost. There is recent anecdotal evidence from call centre staff in India that although these young employees are being paid relatively high sums compared to others, their sleep patterns have altered and they are having difficulties with self-identity. At the same time it is likely that those who aspire to but have not attained similar employment may be feeling left behind, while perceiving the country to be marching onward. Helping employees adjust to new working environments as they move from one career to the next is an important and growing responsibility both of corporations and health professionals. Furthermore, social welfare and policies that protect employees do not preclude productive engagement in open international trade and investment, thus new economic processes should be seen as being compatible with social policies to help individuals adjust to new patterns of working. However, the decline of trade union representation (Munck and Waterman, 2002) is likely to have negative effects on the adjustment and selfesteem of workers for whom protection at work is crucial in forming a sense of worth within the work place. For example, occupational patterns are known to play an important role in the formation and maintenance of personal identities (Fryers, 2006). One can argue that the social and economic processes that attend globalization have profoundly altered the way in which the working world is experienced, whether in the poorer nations, among large corporations or among low income groups in developed countries. 


\section{Identity Shifts}

Many commentators have posited cultural cross-communication as a key factor in the breakdown of economic and social boundaries in the world (Kelly, 2003). Most commentators agree that globalization as a process incorporates a number of facets that range from the economic (the growth of multinational corporations, the primacy of 24 hour trading), to the cultural (the prominence of English as a lingua franca, the dominance of global brands such as Coke and Nike). The influences of these individual factors on mental health should be addressed separately, while keeping in mind the fact that one group of processes very often amends the other. Modalities such as the Internet, film and television are generating new 'hybrid' identities among the young. Young people outside the West are forging identities in the variegated crucible of global culture, influenced by the Internet, music and television (Bargh and McKenna, 2004: 586). Arnett (2002) has suggested that this can lead to identity confusion among individuals. Similarly, he argues that the simultaneous possession of a local (more traditional) and a global identity may be a source of stress, especially in the young. Verma and Saraswathi (2002: 105-40) have examined the behaviour of young Indian professionals in this context. They have found that among this group there is both a successful engagement with a widening global workforce and the display of conduct concomitant with traditional rules of behaviour with regard to marriage and family obligations. These behaviours indicate the deployment of two separate rules of behaviour in the spheres of work and home. When one set of identity relationships is made to interact with another, tension and distress may arise, especially if the meanings of these roles are not clear. Anecdotal evidence suggests that the explosion in call-centre employment in India has increased presentations of substance abuse, domestic problems, depression and anxiety to local psychiatrists (Basu, 2004). This process may disproportionately affect the young, who are more likely to be faced with the pressures of multiple cultural settings.

The anti-globalization movement has been identified in many quarters with the world's youth (Welti, 2002: 276-306). Patterns of conduct among the young in non-western countries have also changed. Nsamenang (2002: 61-104) has described the loosening of sexual restrictions in sub-Saharan Africa, manifested by increased rates of teenage pregnancy and premarital sex, as examples of the influence of globalization on behavioural norms. The young may be more susceptible to stress from growing up within this milieu of cultural multiplicity and uncertainty, while older individuals may experience a damaging sense of loss at the social and cultural changes being wrought in the wake of globalization. Uncertainty and the sense of feeling like a stranger in strange land are recurring themes among anthropological analyses of modernity. Appadurai (1998: 908) has posited that the phenomenon of ethnic violence can be seen as a manifestation of inherent communitarian tensions 
wrought by the deforming effect of globalization processes on local and global boundaries. Planes of identity have shifted from the locally sited to the supralocal, and where boundaries between self and other have become unclear, the use of violent behaviour can accompany the process of delineating the other. Bhugra (2003: 473-4), in a commentary on Kelly (2003: 474), suggests that the degradation of traditional individual and kinship identities and norms of behaviour represents the result of an ongoing process of cultural homogenization. Hence, the relationship between individual identity and social expectation must be seen in its broader cultural context and through the overarching lens of globalization. These identities are crucial in understanding the various stressors placed on individuals in daily life.

Identities are also influenced by the type of society in which one resides, whether individualist or collectivist in nature, an approach/model developed by Hofstede (1984) and Triandis (1995) among others. According to Triandis, collectivist societies tend to view individuals 'primarily as part of a whole, and ... motivated by the norms and duties imposed by the collective entity', while societies that are individualist tend to be driven by individual preferences and needs. Yet within this general scheme, communities and their individual members may differ in their own orientations - individualist societies may have collectivist individuals, and vice versa - thus creating tension (CaldwellHarris and Aycicegi, 2006). Particular orientations are transmitted to members of a community through child-rearing practices and interaction with peers (Asher and Coie, 1990; Rosenthal and Bornholt, 1988). Globalization and its associated expectations are changing the orientations of people, especially the young, through educational and other institutions as well as through peer pressure, thus creating a culture conflict. As global communication allows the spread of beliefs, narratives and ideas across the globe from their point of origin, they displace previously held ways of seeing and explaining the world, contributing to individual and community tensions. This incongruity between individual self concept and the orientation of the local culture (the 'person-culture fit') has been implicated in the increased rates of mental disorder among migrants (Caldwell-Harris and Aycicegi, 2006). However, the model may also apply to individuals in collectivist societies whose outlook is at odds with that of their local milieu, and the consequent development of individual stress. The loss of family cohesion as a result of the migration of fathers and husbands may be more harmful in collectivist societies, where evidence suggests that individual satisfaction is correlated with measures of family satisfaction (Benet-Martinez and Karakitapoglu-Aygun, 2003).

The spread of economic change, including increasing income inequality, further exacerbate these tensions. Gottfredson and Hirschi (1990) suggest that loss of social cohesion has a tendency to increase individual greed and the societal emphasis on individual achievement. There is evidence that the rates of common mental disorders, crime and divorce go up when societies become more individualistic (Maercker, 2001). 
The capacity for global communication associated with globalization, including the Internet, has created new pressures and expectations in societies, particularly those outside the West, in relation to wealth, identity and other factors. What is more, anecdotal evidence also suggests that the progressive individualization of young people is altering traditional methods of social support and monitoring of those who might go on to develop distress. Changes in modes of social support have similarly been implicated in increasing rates of mental disorders (Brown and Harris, 1978). The concept of social capital, roughly defined as 'networks of people deriving benefit from common interaction with each other' (World Bank, 2001), describes the diminution of social cohesion within the local community as being linked to adverse mental health outcomes (McKenzie et al., 2002). Boydell et al. (2001) have used a related concept, anomie, to explain increased rates of schizophrenia among migrant groups. They argue that the progressively more global scale in which political and legislative decisions are made is creating a growing sense of disenfranchisement. Mahadevia (2002) similarly illustrates the way in which economic practices might bring about the reduction of social capital, as the role of the state changes from being welfare-oriented to profit-oriented.

In commenting on higher rates of suicide among adolescents in a South Indian population, Aaron et al. (2004) suggest that conflict between generations and between genders is more problematic among agricultural communities undergoing transformation than in developed countries. The impact of 'global culture' is likely to vary from country to country. Arnett (2002) suggests the concept of cultural distance as a way of characterizing the effect of globalization on individual cultures: the extent to which the culture is different in essence to western culture might determine how problematic global culture is in a particular area. Hofstede et al. (2002) suggest a similar approach.

On an epidemiological level, patterns of psychopathology appear to be changing in certain parts of the world secondary to identifiable economic and cultural changes. Data have linked urbanization with a worsening state of local mental health (Blue et al., 1995). Fijian girls' exposure to television was found to be associated with increased rates of disordered eating behaviour (Becker, 2004). In India, rates of eating disorders and suicide are on the increase, phenomena many have linked to changes in social and cultural mores among young people (Rahim and Cederblad, 1989; Shroff and Thompson, 2004).

\section{Globalization: An Acculturative Stressor?}

Another facet of economic change, that of economic migration, has identifiable effects on mental health within certain settings. Li et al. (2006: 5-13) conducted qualitative interviews with rural to urban migrants in Beijing that revealed feelings of hostility, isolation and poor social adjustment. A dominant theme in the psychiatric discourse on globalization has been the impact of physical 
migration, a manifestation of globalization, on mental disorder. Acculturation has been highlighted as a key model. Acculturation is the process of adapting one's identity to a new cultural environment, which may or may not create stress. In a similar fashion, anthropological models of globalization have tended to focus on the movement of individuals between localities. What these efforts have tended to ignore is the importance of the non-migrant, the static community of individuals around whom cultural symbols move.

It is probable that factors at work among migrants will be similar among those alienated and disenfranchised by globalization. A number of similarities exist between acculturation as it has been applied to migrants and psychological processes that may be occurring among non-migrants resident in communities that are exposed to rapid social and economic change. Both processes entail the apposition of two cultures, with one set of cultural beliefs dominating the other. Globalization has transformed the dynamics of cultural symbols and concepts - the delineation between cultures is less defined than it has ever been. Modes of exposure to different cultures have broadened with new communication methods. Thus acculturation has become a more variegated and complex phenomenon. Increased identity confusion among the young may be entailed by radical changes in the way culture is defined and transmitted from place to place.

We, along with other commentators, have reflected migration as a stressor, and as a mode by which globalization could be exerting negative effects on mental health. However, it should also be kept in mind that migration has had a huge economic impact in the wealth of developing nations - in 2003 money sent home by migrant workers was the largest source of investment in Latin America (Glaister, 2004). More generally, while the transformation of economic practice has important social and cultural effects, globalization has offered, and continues to offer, opportunities for mental health improvement. The continued exchange of researchers between countries will ensure dialogue between research communities and maintain the exchange of 'best practice', while improved access to demographic data in low income countries will allow a better understanding of the mental health profiles of these nations. The development of supra-national approaches to mental health headed by organizations such as the World Health Organization (WHO) and the World Psychiatric Association should allow mental health promotion initiatives to take hold in poorer nations that have borne the brunt of economic shifts. However, despite these opportunities, most observers maintain that the mental health of low income countries is getting worse, not better (WHO, 2000).

\section{Implications}

Organizations and individuals responsible for providing care need to address the fact that where there may have been family support structures in the past, 
many people are likely to be coping with distress alone, or with diminished levels of social support. Volunteers and NGOs (non-governmental organizations) will be factors in providing access to individuals displaced from their local environment for economic reasons. In addition, traditional sources of care must be supported and nurtured. We have discussed social capital as a useful model for doing this, and Cullen and Whiteford (2001) outline a number of ways in which reserves of social capital can be built. These include the strengthening of social networks, investment in NGOs, improving ties between groups normally divided along ethnic, religious or other grounds, and building awareness on the part of decision makers regarding the social outcomes of economic policy. In the specific context of mental health, interventions that address social norms, an important behavioural component of social capital, are likely to be useful. Improved communication networks between policy makers in different countries is likely to help rather than hinder this process - in this way, the globalization of communication should be seen as a distinct asset in the drive to improve the psychological well-being of the world's population. However, the mechanisms by which social capital affects mental health remain poorly understood, and for this reason strategies for improving stocks of social capital must be tentative. The transformation of communications methods has broadened the dimensions of social networks to include groups of individuals that are geographically dispersed, so that we can now discuss stocks of social capital among 'communities without propinquity'; delineation of the varied dimensions of social capital must continue apace. Communities wherein people feel in control at work are likely to invest more trust in social life both inside and outside of employment settings. We argue that investment in social capital in areas with social inequality could have major effects not only on status perceptions, but also on psychological well-being.

\section{MENTAL HEALTH POLICY AND GLOBALIZATION: REACHING}

BEYOND STUDIES ON MIGRANTS

We argue therefore for a re-evaluation of mental health policy in view of globalization, one that would look further than migrants, on whom the greater part of mental health interest has been focused, and address indigenous communities where modes of social experience and behaviour are changing. For example, Nasser (1997) asserted that the emergence of anorexia nervosa in non-western countries is attributable to the progressive appropriation of western ideals of thinness in these countries. Bemporad (1996) suggested that eating disorders 'are the price paid for Western civilization' while AbouhSaleh et al. (1998) have blamed increasing westernization for the incidence of anorexia nervosa in Arab cultures. However, Rieger et al. (2001) have pointed out that studies of non-western individuals have been contradictory in their analysis of the links between westernization and eating psychopathology. While it is likely that increasing exposure to western culture has played a role in changing aspirations and ideals in much of the rest of the world, the nature 
and substrate of 'westernization' remain unclear, as does the question of whether western culture can ever be dissociated from the material benefits of trade between nations. The appropriation of western patterns of alcohol consumption, in parallel with alterations in traditional systems of authority, has been linked to increased amounts of hazardous drinking in the developing world (WHO, 2002). The epidemic of suicide among farmers in Warangal in the state of Andhra Pradesh in South India was explicitly linked to the liberalization of agriculture and raises important questions of responsibility - who should provide social support for agricultural workers who lose out to global corporations (Shiva, 2004)?

The relationship between migrants and other, non-migratory individuals in the global world is complex. On one level, the process of acculturation may also be at work as egocentric individuals struggle to come to terms with collectivist orientations in their local culture, in the same way that migrants are exposed to acculturative stress when they reach the new country. In fact, many of the stressors described among new migrants are identical to those likely to be operating among individuals in low income countries exposed to the loss of social cohesion and social capital. A feeling of isolation from the prevalent cultural mores is likely to be present in many cases in both situations, among the migrant and non-migratory individual, particularly the young, outside the West. Added to this will be a possible lack of previously relied-upon safety nets, such as extended family and religious communities for individuals who find themselves in distress. In the West, the work of Galea et al. (2001) has supported the role of social support in protecting against psychiatric morbidity. In particular, the awareness of cultural differences in health belief models should be accounted for in policy making. Locally, social networks, such as voluntary counselling services, religious groups, Internet groups and extended family networks should be identified and nurtured in the face of rapid social and economic transformation.

A shift of emphasis towards occupational mental health issues is also necessary in order to account for the undoubted effects of patterns of employment and income on mental health. The role of multinational corporations in providing mental health support for its employees and their families needs to be addressed. From a national point of view, mental health professionals need to be in a position to advise governments about the psychological effects of economic change and remind them of the universal human rights with respect to mental illness (Kelly, 2003). Beyond the implementation of financially viable mental health interventions in low income countries (Patel et al., 2003; Sumathipala et al., 2000), the specific character of appropriate psychological therapies may also need to acknowledge and adapt factors that have been shaped by globalization phenomena - such as changing patterns of social support and increasing disenfranchisement, as well as increasing financial worries. This could entail an improved awareness on the part of individual caregivers, or changes in the ways therapeutic encounters are integrated into 
wider care plans. However, incorporating and working alongside traditional health belief models and systems of care will also be important.

Schoenbaum et al. (2001) showed that two quality improvement interventions performed to ameliorate management of depression in a primary care setting in the USA were able to improve work attendance and reduce the total burden of depression. These interventions were found to be cost-effective for employers purchasing the health care. Interventions that incorporated training for health professionals, enhanced educational resources and therapeutic follow-up, in the form of cognitive behavioural therapy or psychotherapy, had statistically significant effects on labour supply, providing one additional month of employment over a two-year period. While this American study does not replicate the conditions of the developing world, the economic argument for investment in the treatment of mental disorders needs to be based on further research into the possible cost benefits to corporations of mental health care for their workforce. In an era of transforming working environments with potentially damaging effects on mental health, there needs to be detailed consideration of the balance between productivity and good psychological functioning and health professionals must be at the forefront of this debate. In an Australian review, Dollard and Winefield (2002) have pointed out the high cost of stress-related problems in the form of employee compensation claims. The significant cost of stress-related claims could be offset by an increased focus on reducing stressful conditions at work.

Not only should we reflect on the impact of increasing levels of international migration on national and community identities, but also the impact of social and cultural transformation on lived experience in low income countries, where the speed of such change appears to be greatest. Economic liberalization should be embraced insofar as it is a way of generating wealth and productivity for the world's poorest nations, but with it should come an acute awareness of the wider effects of economic transformation on the way in which we work and live. In addition, a new understanding of the role of family support and the social impact of displacement needs to be fashioned.

Observers from a range of disciplines have portrayed a globalized world becoming progressively more populated by 'strangers', in the form of political refugees, economic migrants, guests and so on. However, we also know that transformed channels of communication have altered the social experience for people outside the developed world, especially the young (Arnett, 2002). Could it be that indigenous individuals and the communities that support them are feeling as delocalized as those who migrate? There is also responsibility therefore to think more broadly about the effects of globalization on all individuals, not only those located in low income countries, or those who have migrated.

Much of this discussion has involved issues of identity, but as western illness models and therapies spread, what effect will the globalization of psychiatry have on the provision of a framework of care that respects and accommodates different orientations? Timimi (2005) has argued that the notion of 'psychiatry' 
is an intrinsically western construct and its application to populations outside the West amounts to an unhealthy imposition of a 'problematic' health belief system. Would a psychiatry applied to the non-western world risk exacerbating the problems of identity formation that it seeks to treat? It remains difficult to say whether culturally appropriate modes of mental health care are being provided in cultures outside the West (Ohaeri and Fido, 2001; Pereira et al. (2007). In a qualitative investigation of women with depression in Goa, Pereira et al. (2007) found that interviewees typically expressed their problems through somatic complaints. Somatization of psychological distress has been characterized in a number of developing country settings (Aidoo and Harpham, 2001; Turkson and Dua, 1996) and should therefore be at the forefront of any coherent mental health policy in these countries. Policy on mental health must be joined up to that of physical health in a holistic strategy to address the often confusing and porous boundaries between the two.

\section{Concluding Remarks}

Globalization, if it is anything, is a multidimensional phenomenon. While the potential disadvantages of economic change for mental health are clear, this needs to be considered in the context of an individual's identity and the orientation of their local community. Economic transformations, manifest in the transformation of labour markets, the rise of the informal sector and increasing inequalities will continue to have a stressing influence unless there are mechanisms and policies put in place to help communities to adjust to new realities. Support should come from governments and NGOs as well as employers themselves. However, these stress factors do not operate in a vacuum. Any interventions should be underpinned by an integrated understanding of 'globalization' as a disparate array of enmeshed social, economic and cultural processes. For example, the vulnerability of individuals to occupational stress will depend on the nature of their social support networks and the fit between an individual's identity and the orientation of their local community. It could be that we are seeing manifestations of social and cultural transition in the increased rates of particular mental disorders outside the West. A programme for ongoing research is needed in order to fully comprehend the complexity of these shifting identities and patterns of experience, both on the individual and community level, and to ensure that local contexts are not lost in the morass of bottom line calculations.

\section{ACKNOWLEDGEMENTS}

The authors acknowledge financial support from the Department of Health via the National Institute for Health Research (NIHR) Specialist Biomedical Research Centre for Mental Health Award to South London and Maudsley NHS Foundation Trust (SLaM) and the Institute of Psychiatry at King's College London. 
REFERENCES

Aaron, R., Joseph A., Abraham, S., Muliyil, J., George, K., Prasad, J., Minz, S., Abraham, V.J. and Bose, A. (2004) 'Suicides in Young People in Rural Southern India', Lancet 363(9415): 1117-18.

Abou-Saleh, M.T., Younis, Y. and Karim, L. (1998) 'Anorexia Nervosa in an Arab Culture', International Fournal of Eating Disorders 23(2): 207-12.

Aidoo, M. and Harpham, T. (2001) 'The Exploratory Models of Mental Health Amongst Low-Income Women and Health Care Practitioners in Lusaka, Zambia', Health Policy and Planning 16: 206-13.

American Psychiatric Association (2000) Diagnostic and Statistical Manual of Mental Disorders (4th edn). Washington, DC: American Psychiatric Association.

Appadurai, A. (1998) 'Dead Certainty: Ethnic Violence in the Era of Globalization', Development and Change 29(4): 905-25.

Arnett, J.J. (2002) 'The Psychology of Globalization', American Psychologist 57(10): $774-83$.

Asher, S. and Coie, J. (eds) (1990) Peer Rejection in Childhood. Cambridge: Cambridge University Press.

Bargh, J. and McKenna, K. (2004) 'The Internet and Social Life', Annual Review of Psychology 55: 573-90.

Basu, I. (2004) The Faces of Globalization: A Dilemma for India, accessed 17 November 2007, http://www.spacedaily.com/news/india-04e.html

Becker, A.E. (2004) 'Television, Disordered Eating, and Young Women in Fiji: Negotiating Body Image and Identity During Rapid Social Change', Culture, Medicine and Psychiatry 28(4): 533-59.

Bemporad, J.R. (1996) 'Self-Starvation Through the Ages: Reflections on the PreHistory of Anorexia Nervosa', International Fournal of Eating Disorders 19(3): 217-37.

Beneria, L. (2001) 'Shifting the Risk: New Employment Patterns, Informalization and Women's Work', International fournal of Politics, Culture and Society 15(1): 27-53.

Benet-Martinez, B. and Karakitapoglu-Aygun, Z. (2003) 'The Interplay of Cultural Syndromes and Personality in Predicting Life Satisfaction: Comparing Asian Americans and European Americans', Journal of Cross-Cultural Psychology 34(1): 38-60.

Bhugra, D. (2003) 'Invited Commentary on Globalisation and Psychiatry', Advances in Psychiatric Treatment 9(6): 473-4.

Bhugra, D. and Mastrogianni, A. (2004) 'Globalisation and Mental Disorders: Overview with Relation to Depression', British fournal of Psychiatry 184(1): 10-20.

Blue, I., Ducci, M., Jaswal, S., Ludermir, A. and Harpham, T. (1995) 'The Mental Health of Low Income Urban Women', in T. Harpham and I. Blue, I. (eds) Urbanization and Mental Health in Developing Countries (pp. 75-102). Aldershot: Avebury.

Boydell, J., Van Os, J., McKenzie, K., Allardyce, J., Goel, R., McCreadie, R.G. and Murray, R.M. (2001) 'Incidence of Schizophrenia in Ethnic Minorities in London: Ecological Study into Interactions with Environment', British Medical fournal 323(7325): 1336-8.

Brown, E. and Harris, T. (1978) Social Origins of Depression. London: Tavistock.

Caldwell-Harris, C.L. and Aycicegi, A. (2006) 'When Personality and Culture Clash: The Psychological Distress of Allocentrics in an Individualist Culture and Idiocentrics in a Collectivist Culture', Transcultural Psychiatry 43(3): 331-61.

Capelli, P. (1999) The New Deal at Work. Boston, MA: Harvard Business School Press.

Charlesworth, S.J., Gilfillan, P. and Wilkinson, R. (2004) 'Living Inferiority', British Medical Bulletin 69(1): 49-60. 
Cullen, M. and Whiteford, H. (2001) 'The Interrelations of Social Capital with Health and Mental Health: Discussion Paper'. Australia: National Mental Health Strategy.

Deaton, A. and Lubotsky, D. (2003) 'Mortality, Inequality and Race in American Cities and States', Social Science \& Medicine 56(6): 1139-53.

Dicken, P. (1998) Global Shift: Transforming the World Economy. New York: The Guildford Press.

Dollard, M. and Winefield, A. (2002) 'Mental Health: Overemployment, Underemployment, Unemployment and Heathy Jobs', AefAMH 1(3): 1-26.

Economist, The (2000a), 29 January.

Economist, The (2000b), 10 June.

Eibner, C., Sturn, R. and Gresenz, C.R. (2004) 'Does Relative Deprivation Predict the Need for Mental Health Services?', Journal of Mental Health Policy Economics 7(4): $167-75$.

Fryers, T. (2006) 'Work, Identity and Health', Clinical Practice of Epidemological Mental Health 31(2): 12.

Galea, S., Ahern, J., Resnick, H., Kilpatrick, D., Bucuvulas, M., Gold, J. and Vlahur, D. (2002) 'Psychological Sequelae of the September 11th Terrorist Attacks in New York City', New England fournal of Medicine 346(13): 982-7.

Glaister, D. (2004) 'Emigrants Provide Lifeline to Latin America', Guardian (31 March): 15 .

Gottfredson, M. and Hirschi, T. (1990) A General Theory of Crime. Stanford, CA: Stanford University Press.

Grint, K. (2005) The Sociology of Work. London: Polity Press.

Hofstede G. (1984) Culture's Consequences. London: Sage.

Hofstede G.R., Pedersen, P.B. and Hofstede, G. (2002) Exploring Culture: Exercises, Stories and Synthetic Cultures. Yarmouth, Maine: Intercultural Press.

Human Development Report (2001). New York: United Nations.

International Labour Organisation (ILO) (1999) Panorama Laboral 99. Lima: ILO.

Kahn, R.S., Wise, P.H., Kennedy, B.P. and Kawachi, I. (2000) 'State Income Inequality, Household Income, and Maternal Mental and Physical Health: CrossSectional National Survey', British Medical fournal 321(7272): 1311-15.

Katz, H.C. (2000) Converging Divergencies: Worldwide Changes in Employment Systems. Ithaca, NY: Cornell University Press.

Kelly, B. (2003) 'Globalisation and Psychiatry', Advances in Psychiatric Treatment 9: 464-70.

Kohl, R. and O'Rourke, K. (2000) What's New About Globalization: Implications for Income Inequality in Developing Countries: A Policy Dialogue on the Effects of Globalization. Paris: Organisation for Economic Co-operation and Development.

Li, X., Stanton, B., Fang, X. and Lin, D. (2006) 'Social Stigma and Mental Health Among Rural-to-Urban Migrants in China: A Conceptual Framework and Future Research Needs', World Health and Population 8(2): 1-18.

Lynch, J., Smith, G.D., Harper, S., Hillemeier, M., Ross, N., Kaplan, G.A. and Wolfson, M. (2004a) 'Is Income Inequality a Determinant of Population Health? Part 1. A Systematic Review', Milbank Quarterly 82(1): 386-91.

Lynch, J., Smith, G.D., Harper, S. and Hillemeier, M. (2004b) 'Is Income Inequality a Determinant of Population Health? Part 2. US National and Regional Trends in Income Inequality and Age- and Cause-Specific Mortality', Milbank Quarterly 82(2): $355-400$.

McKenzie, K., Whitley, R. and Weich, S. (2002) 'Social Capital and Mental Health', British Fournal of Psychiatry 181(4): 280-3. 
Maercker, A. (2001) 'Association of Cross-Cultural Differences in Psychiatric Morbidity with Cultural Values: A Secondary Analysis', German fournal of Psychiatry 4(1): 17-23.

Mahadevia, D. (2002) 'Communal Space Over Life Space; Saga of Increasing Vulnerability in Ahmedabad', Economic and Political Weekly 37(48): 4850-8.

Marmot, M. (2004) Status Syndrome: How your Social Standing Directly Affects your Health and Life Expectancy. London: Bloomsbury.

Martin, G. (2005) 'Editorial: Globalization and Health', Globalization and Health 1(1): 1-2.

Munck, R. (1999) 'Labour Dilemmas and Labour Futures', in R. Munck and P. Waterman (eds) Labour Worldwide in the Era of Globalisation: Alternative Union Models in the New World Order (pp. 3-26). London: Macmillan.

Munck, R. and Waterman, P. (eds) (1998) Labour Worldwide in the Era of Globalisation. London: Macmillan.

Muntaner, C., Li, Y., Xue, X., O’Campo, P., Chung, H.J. and Eaton, W.W. (2004) 'Work Organization, Area Labor-Market Characteristics, and Depression Among US Nursing Home Workers: A Cross-Classified Multilevel Analysis', International Fournal of Occupational and Environmental Health 10(4): 392-400.

Muntaner, C., Li, Y., Xue, X., Thompson, T., O’Campo, P., Chung, H. and Eaton, W.W. (2006) 'County Level Socioeconomic Position, Work Organization and Depression Disorder: A Repeated Measures Cross-Classified Multilevel Analysis of Low-Income Nursing Home Workers', Health \& Place 12(4): 688-700.

Nasser, M. (1997) Culture and Weight Consciousness. London: Routledge.

Niedhammer, I., Tek M.L., Starke, D. and Siegrist, J. (2004) 'Effort-Reward Imbalance Model and Self-Reported Health: Cross-Sectional and Prospective Findings from the GAZEL Cohort', Social Science Medicine 58(8): 1531-41.

Niedhammer, I., Chastang, J.F., David, S., Barouhiel, L. and Barrandon, G. (2006) 'Psychosocial Work Environment and Mental Health: Job-Strain and Effort-Reward Imbalance Models in a Context of Major Organizational Changes', International Fournal of Occupational and Environmental Health 12(2): 111-19.

Nsamenang, B. (2002) 'Adolescence in Sub-Saharan Africa: An Image Constructed from Africa's Triple Inheritance', in B.B. Brown, R. Larson and T.S. Saraswathi (eds) The World's Youth: Adolescence in Eight Regions of the Globe (pp. 61-104). New York: Cambridge University Press.

Ohaeri, J.U. and Fido A.A. (2001) 'The Opinion of Caregivers on Aspects of Schizophrenia and Major Effective Disorders in a Nigerian Setting', Social Psychiatry and Psychiatric Epidemiology 36(10): 493-9.

Okasha, A. (2005) 'Editorial: Globalization and Mental Health: A WPA Perspective', World Psychiatry 4(1): 1-2.

Osler, M., Prescott, E., Gronbaek, M., Christensen, U., Due, P. and Engholm, G. (2002) 'Income Inequality, Individual Income, and Mortality in Danish Adults', British Medical fournal 324(7328): 13-16.

Patel, V., Chisholm, D., Rabe-Hesketh, S., Dias-Saxena, F., Andrew, G. and Mann, A. (2003) 'Efficacy and Cost-Effectiveness of Drug and Psychological Treatments for Common Mental Disorders in General Health Care in Goa, India: A Randomised Controlled Trial', Lancet 361(1): 33-9.

Pereira, B., Andrew, G., Pednekar, S., Pai, R., Pelto, P. and Patel, V. (2007) 'The Explanatory Models of Depression in Low Income Countries: Listening to Women in India', Fournal of Affective Disorders 102(1-3): 209-18.

Pickett, K.E., James, O.W. and Wilkinson, R.G. (2006) 'Income Inequality and the Prevalence of Mental Illness: A Preliminary International Analysis', Fournal of Epidemiological Community Health 60(7): 646-7. 
Rahim, S.I.A. and Cederblad, M. (1989) 'Epidemiology of Mental Disorders in Young Adults of a Newly Urbanised Area in Khartoum, Sudan', British fournal of Psychiatry 155: 44-7.

Rieger, E., Touyz, S., Swain, T. and Beumont, P. (2001) 'Cross-Cultural Research on Anorexia Nervosa: Assumptions Regarding the Role of Body Weight', International Fournal of Eating Disorders 29(2): 205-15.

Rosenthal, D. and Bornholt, L. (1988) 'Expectations about Development in Greek and Anglo-Australian Families', Journal of Cross-Cultural Psychology 19(1): 19-34.

Schoenbaum, M., Unützer, J., Sherbourne, C., Duan, N., Rubenstein, L.V., Miranda, J., Meredith, L.S., Carney, M.F. and Wells, K. (2001) 'Cost-Effectiveness of Practice-Initiated Quality Improvement for Depression: Results of a Randomized Controlled Trial', Fournal of the American Medical Association 19, 286(11): 1325-30.

Shariff, I. (2003) 'Global Economic Integration: Prospects and Problems', International Fournal of Development Economics. Development Review 1(2): 163-78.

Shiva, V. (2004) 'The Suicide Economy of Coporate Globalization', accessed 17 November 2007, http://www.zmag.org/sustainers/content/2004-02/19shiva.cfm

Shroff, H. and Thompson, J.K. (2004) 'Body Image and Eating Disturbance in India: Media and Interpersonal Influences', International Fournal of Eating Disorders 35(2): 198-203.

Stansfeld, S. and Candy, B. (2006) 'Psychosocial Work Environment and Mental Health: A Meta-Analytic Review', Scandinavian fournal of Work, Environment and Health 32(6): 443-62.

Sturm, R. and Gresenz, C.R. (2002) 'Relationship of Income Inequality and Family Income to Chronic Medical Conditions and Mental Health Disorders: National Survey', British Medical fournal 324(1): 2-5.

Subramanian, S.V. and Kawachi, I. (2004) 'Income Inequality and Health: What Have We Learned So Far?', Epidemiological Review 26(1): 78-91.

Sumathipala, A., Hewege, S., Hanwella, R. and Mann, H. (2000) 'Randomized Controlled Trial of Cognitive Behaviour Therapy for Repeated Consultations for Medically Unexplained Complaints: A Feasibility Study in Sri Lanka', Psychological Medicine 30(4): 747-57.

Timimi, S. (2005) 'Effect of Globalisation on Children's Mental Health', British Medical fournal 2, 331(7507): 37-9.

Triandis, H.C. (1995) Individualism and Collectivism. Boulder, CO: Westview Press.

Turkson, S.N. and Dua, A.N. (1996) 'A Study of the Social and Clinical Characteristics of Depressive Illness Among Ghanaian Women (1988-1992)' West African fournal of Medicine 15(2): 85-90.

Upjohn Institute (1997) Employment Research (Newsletter): 4.

Verma, S. and Saraswathi, T.S. (2002) 'Adolescents in India: Street Urchins or Silicon Valley Millionaires?', in B.B. Brown, R. Larson and T.S. Saraswathi (eds) The World's Youth: Adolescence in Eight Regions of the Globe (pp. 105-40). New York: Cambridge University Press.

Weich, S., Lewis, G. and Jenkins, S.P. (2001) 'Income Inequality and the Prevalence of Common Mental Disorders in Britain', British fournal of Psychiatry 178: 222-7.

Welti, C. (2002) 'Adolescents in Latin America: Facing the Future with Skepticism', in B.B. Brown, R. Larson and T.S. Saraswathi (eds) The World's Youth: Adolescence in Eight Regions of the Globe (pp. 276-306). New York: Cambridge University Press.

Wilkinson, R.G. (2004) 'Why is Violence More Common Where Inequality is Greater?', Annals of the New York Academy of Sciences 1036(1): 1-12.

Wilkinson, R.G. (2005) The Impact of Inequality: How to Make Sick Societies Healthier. New York: New Press. 
Wilkinson, R.G. and Pickett, K.E. (2006) 'Income Inequality and Population Health: A Review and Explanation of the Evidence', Social Science Medicine 62(7): 1768-84. Winefield, A.H., Montgomery, B., Gault, U., Muller, J., O'Gorman, J., Reser, J. and Roland, D. (2002) 'The Psychology of Work and Unemployment in Australia Today: An Australian Psychological Society Discussion Paper', Australian Psychologist 37(1): 1-9.

World Bank (2001) World Development Report 2000/2001: Attacking Poverty. Washington, DC: World Bank.

World Health Organization (WHO) International Consortium in Psychiatric Epidemiology (2000) 'Cross-National Comparisons of the Prevalences and Correlates of Mental Disorders', Bulletin of the World Health Organization 78: 413-26.

RÉS UMÉ

\section{Globalisation: Santé Mentale et Facteurs Sociaux-économiques}

Plusieurs facteurs associés à la globalisation ont des conséquences sur la santé mentale. Dans cet article, avant d'analyser le rôle de la globalisation comme à cause de son incidence sur l'acculturation, on examine la documentation disponible sur la santé mentale et les questions d'inégalité, tendances professionnelles, et un changement d'identité. On argue du fait qu'une réévaluation de la politique de santé mentale à la lumière de globalisation, doit avoir une portée qui dépasse celle des études actuelles des migrants et de déterminer les collectivités autochtones où les modes d'expérience et de comportement sociale changent.

\section{RESUMEN}

\section{La Globalización: La Salud Mental y los Factores Económicos Sociales}

Algunos factores que asociamos con la globalización tienen consecuencias en el campo de la salud mental. Este documento examina el material publicado sobre la salud mental y la desigualdad, las pautas profesionales, y los cambios de identidad, antes de considerar el papel de la globalización como un estresor aculturativo. Sostenemos que una reconsideración de la política de la salud mental en vista de la globalización debe examinar más alla de los estudios actuales realizados entre los trabajadores extranjeros: debe considerar las comunidades indígenas donde los medios de experiencia y comportamiento social se están cambiando.

\section{BIOGRAPHICAL NOTES}

VISHAl BHAVSAR is a Senior House Officer in Psychiatry at Guy's Hospital in London. Please address correspondence to: Vishal Bhavsar, SHO Psychiatry, Guy's and St Thomas' NHS Foundation Trust, Guy's Hospital, London SE1 9RT, UK. [email vishal.bhavsar@gstt.nhs.uk]

DINESH BHUgRa is Professor of Mental Health and Cultural Diversity at the Institute of Psychiatry, King's College London. Please address correspondence to: Dinesh Bhugra, Institute of Psychiatry, King's College London, London SE5 8AF, UK. [email: d.bhugra@iop.kcl.ac.uk] 